\title{
Echocardiographic features of impaired left ventricular diastolic function in Chagas's heart disease
}

\author{
IVAN COMBELLAS, „ JUAN J PUIGBO,†‡ HARRY ACQUATELLA,† FRANCISCO \\ TORTOLEDO, „ JOSE R GOMEZ† \\ From the $\star$ University Hospital; the + Cardiological Service, Department of Medicine and School of Medicine; and the \\ $\ddagger$ Cardiovascular Diseases Department, Ministry of Public Health, Caracas, Venezuela
}

SUMmaRY To study left ventricular diastolic function in Chagas's disease, simultaneous echocardiograms, phonocardiograms, and apexcardiograms were recorded in 20 asymptomatic patients with positive Chagas's serology and no signs of heart disease (group 1), 12 with Chagas's heart disease and symptoms of ventricular arrhythmia but no heart failure (group 2), 20 normal subjects (group 3), and 12 patients with left ventricular hypertrophy (group 4). The recordings were digitised to determine left ventricular isovolumic relaxation time and the rate and duration of left ventricular cavity dimension increase and wall thinning. In groups 1 and $2(a)$ aortic valve closure $\left(A_{2}\right)$ and mitral valve opening were significantly delayed relative to minimum dimension and were associated with prolonged isovolumic relaxation, $(b)$ left ventricular cavity size was abnormally increased during isovolumic relaxation and abnormally reduced during isovolumic contraction, and (c) peak rate of posterior wall thinning and dimension increase were significantly reduced and duration of posterior wall thinning was significantly prolonged; both of these abnormalities occurred at the onset of diastolic filling. These abnormalities were more pronounced in group 2 and were accompanied by an increase in the height of the apexcardiogram "a" wave, an indication of pronounced atrial systole secondary to end diastolic filling impairment due to reduced left ventricular distensibility. Group 4, which had an established pattern of diastolic abnormalities, showed changes similar to those in group 2; however, the delay in aortic valve closure $\left(A_{2}\right)$ and in mitral valve opening and the degree of dimension change were greater in the latter group.

Thus early isovolumic relaxation and left ventricular abnormalities were pronounced in the patients with Chagas's heart disease and may precede systolic compromise, which may become apparent in later stages of the disease. The digitised method is valuable in the early detection of myocardial damage.

There is increasing evidence ${ }^{1-3}$ that left ventricular relaxation and filling abnormalities may be an important component of impaired cardiac function, particularly in patients with ischaemic heart disease and ventricular hypertrophy, above all when associated with inco-ordinate left ventricular contraction. 45

In early Chagas's heart disease, angiographic, echocardiographic, and radionuclide studies ${ }^{6-8}$ have detected left ventricular abnormalities consisting of kinetic disorders, especially in the apical or apicopos-

Requests for reprints to Dr Juan J Puigbo, Instituto Diagnostico, Av Anauco, San Bernardino, Caracas 1010, Venezuela.

Accepted for publication 30 October 1984 terior areas, similar to those found in ischaemic heart disease. More recently, left ventricular cineangiography of patients with Chagas's heart disease has shown progressive segmental wall abnormalities and decreased left ventricular distensibility associated with the deterioration in clinical status. ${ }^{9}$ In our laboratory, using non-invasive methods (phonocardiography) we found prolongation of the rapid relaxation period in patients in the early stages of Chagas's heart disease. ${ }^{10}$

The purpose of this study was to detect abnormalities of left ventricular diastolic function at rest in patients with early Chagas's heart disease and normal systolic time intervals by studying relaxation, left ventricular filling, and posterior wall dynamics using 

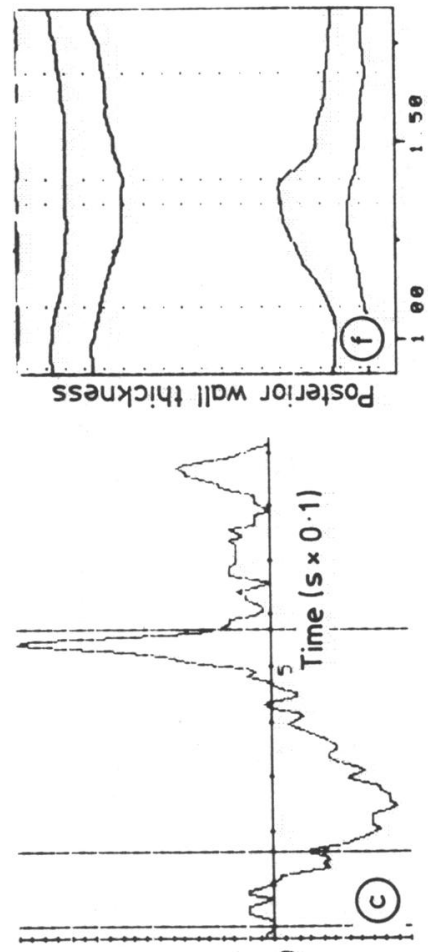

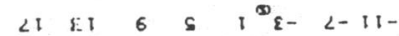

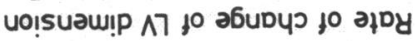
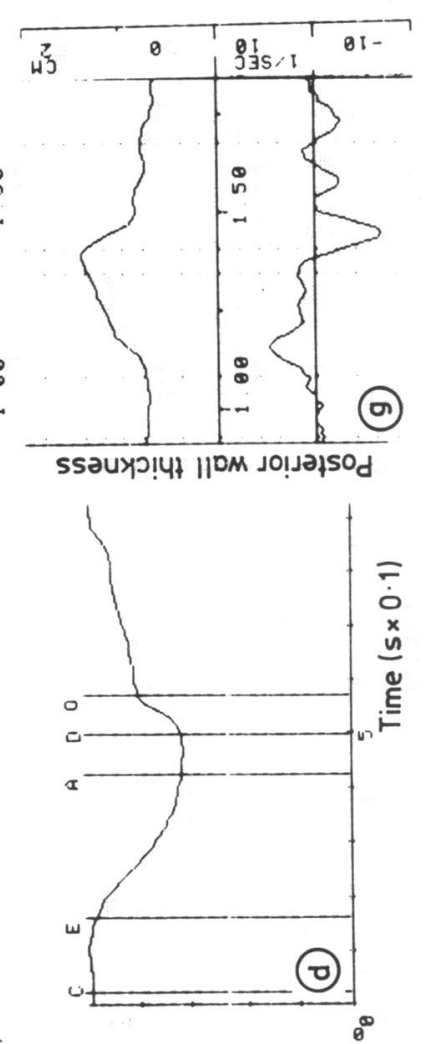

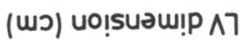
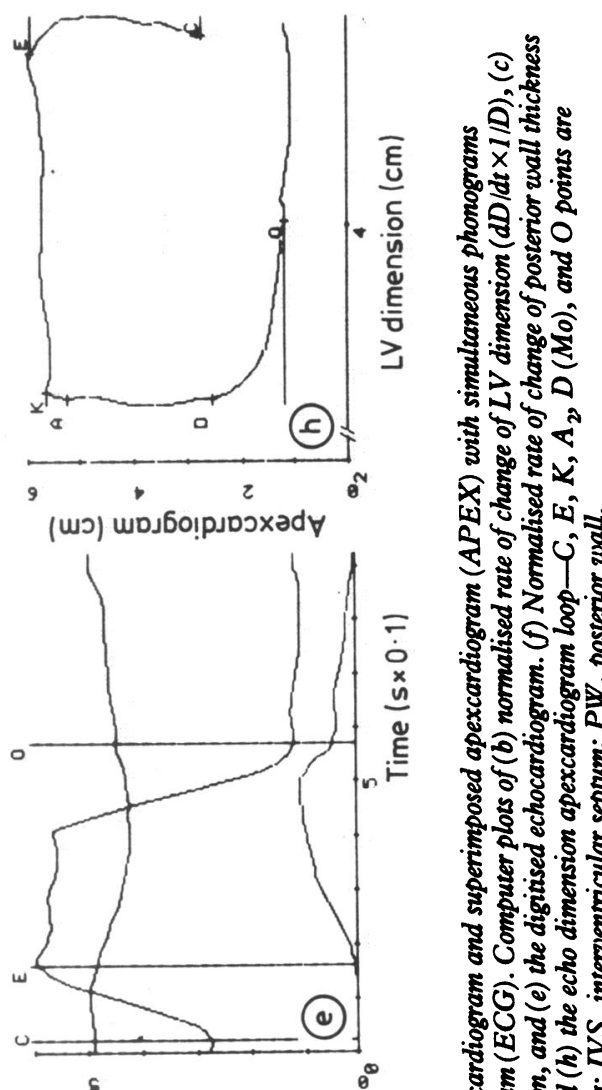

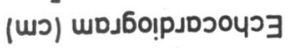
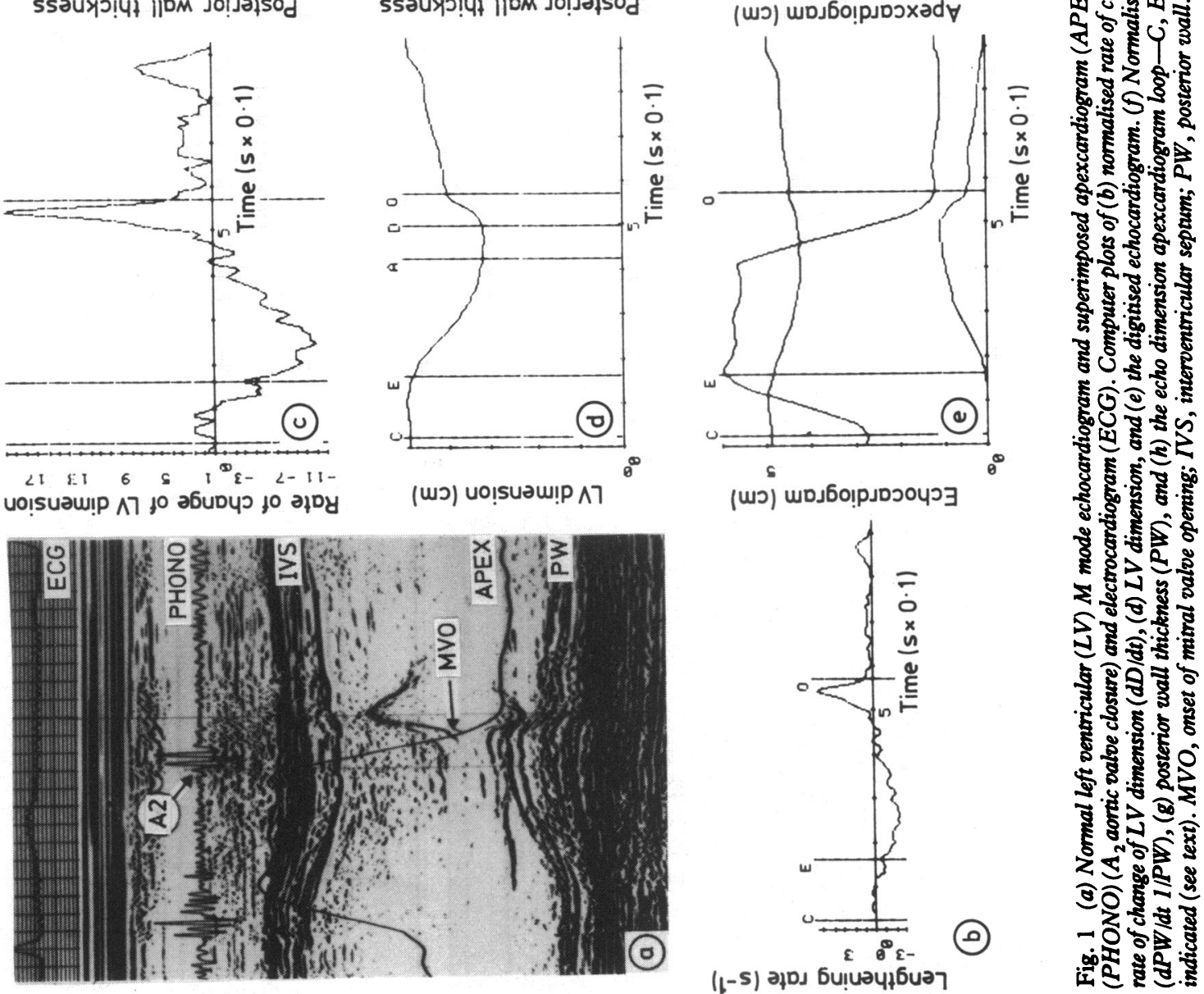

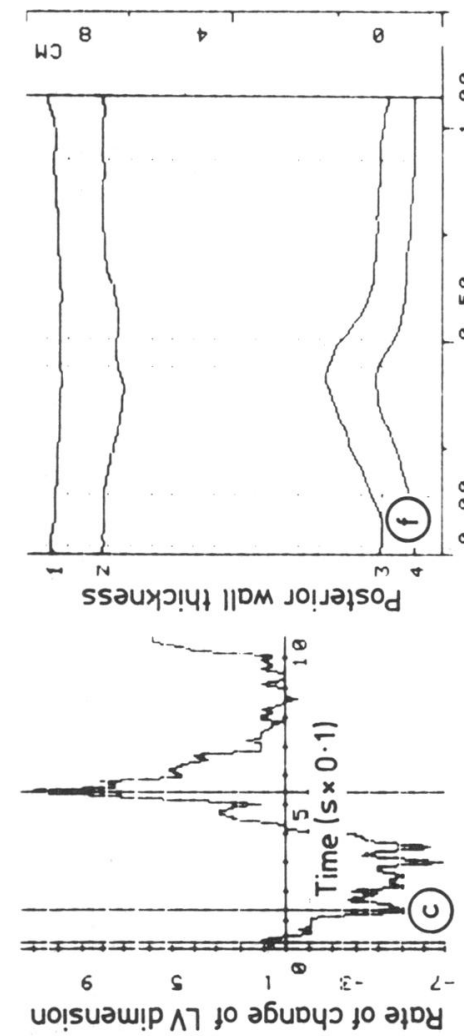
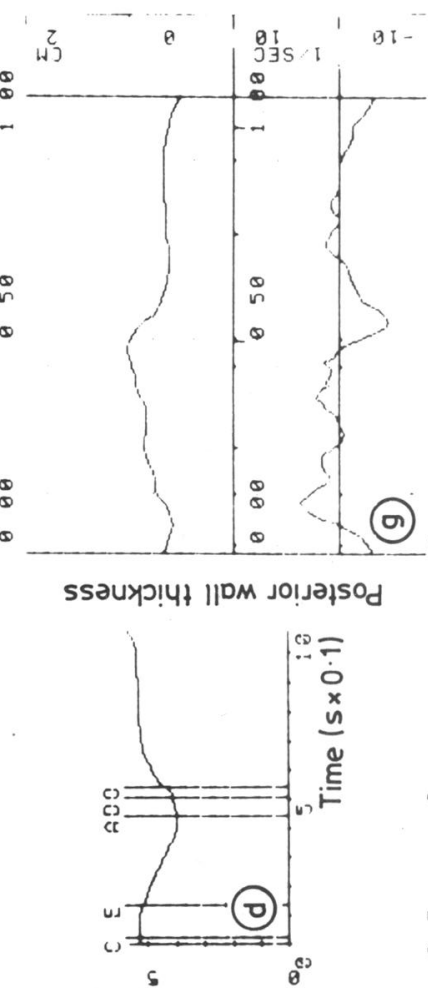

(யว) บo!̣suəแ!̣ $\wedge 7$
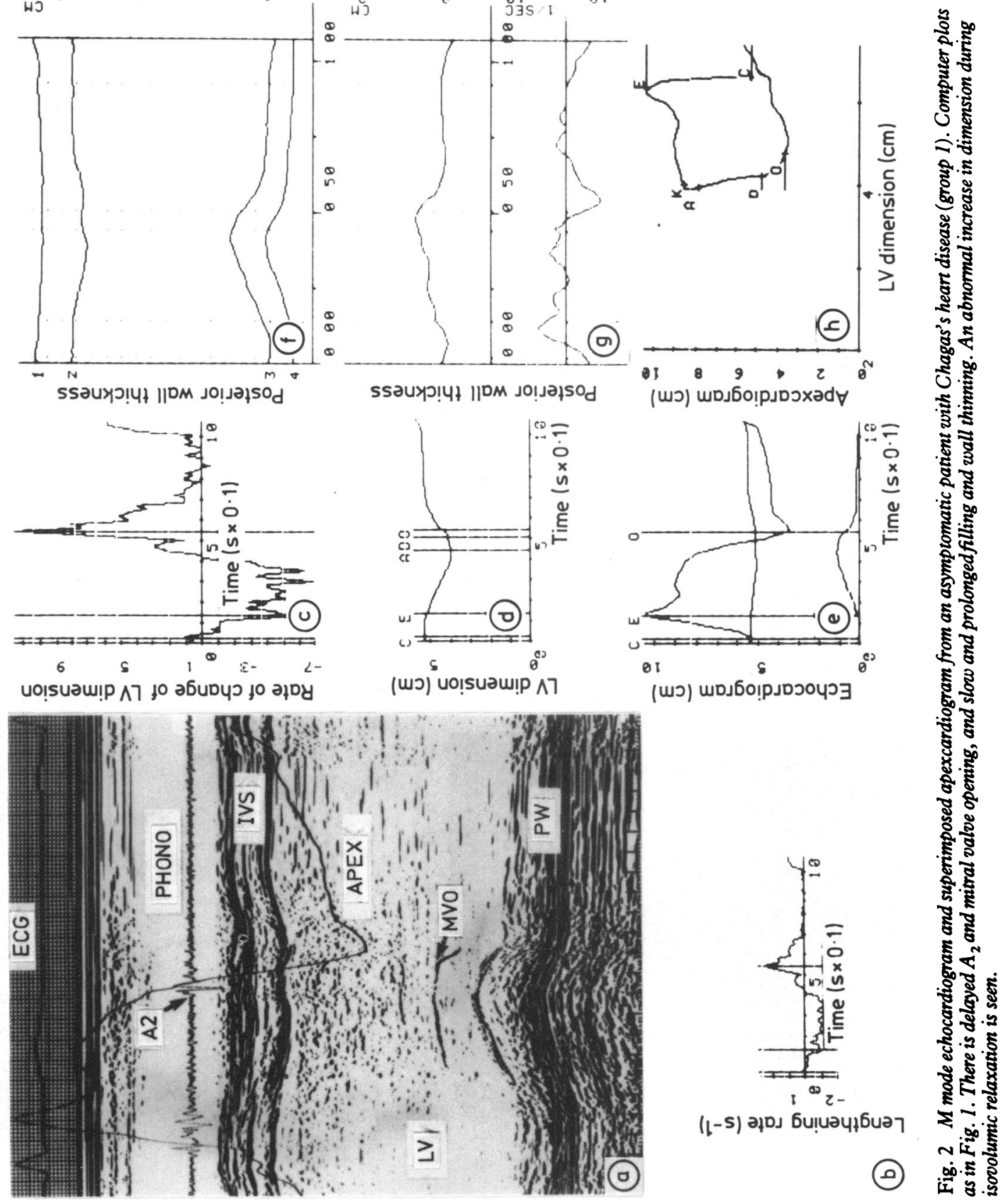

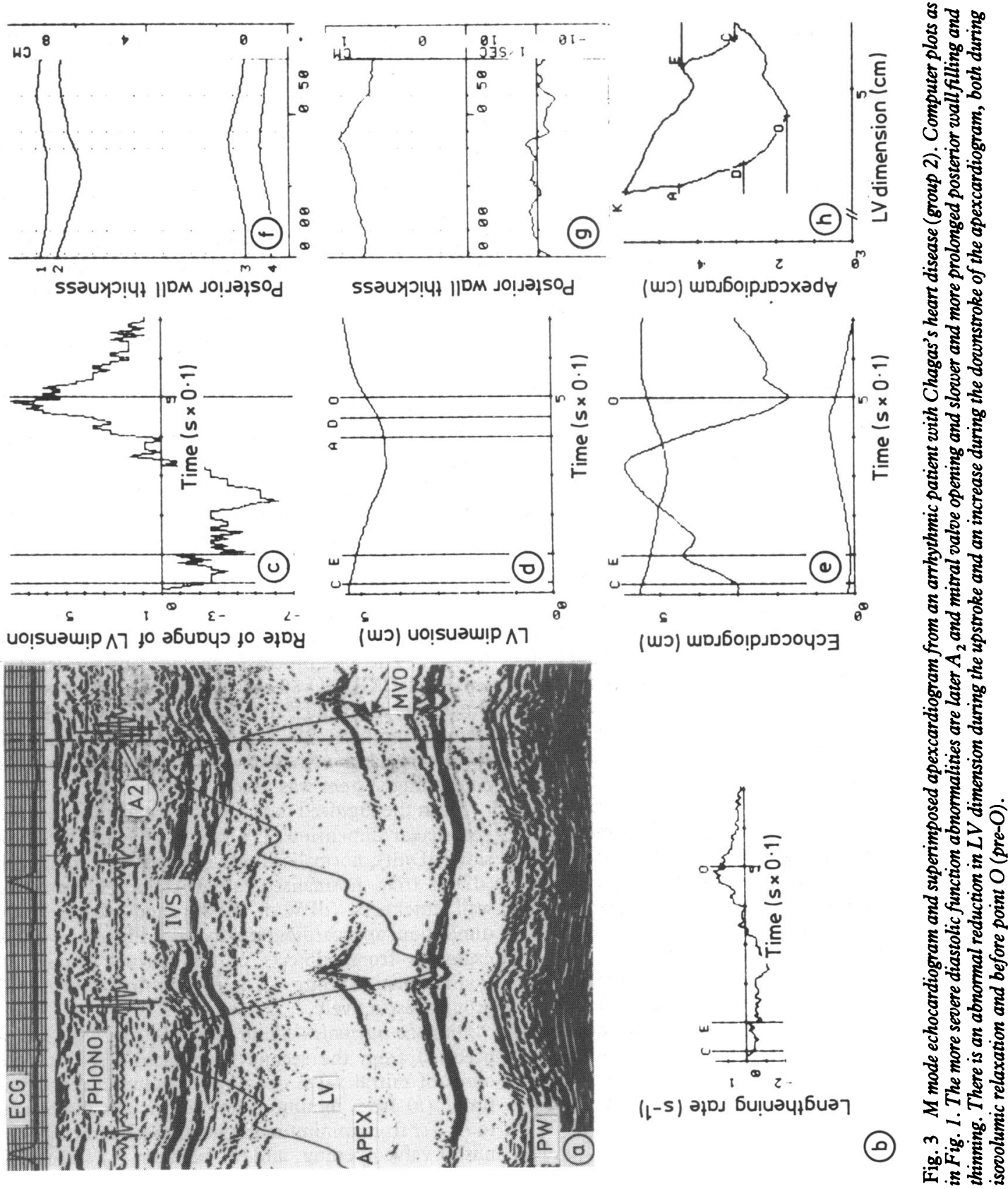

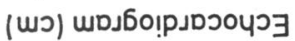

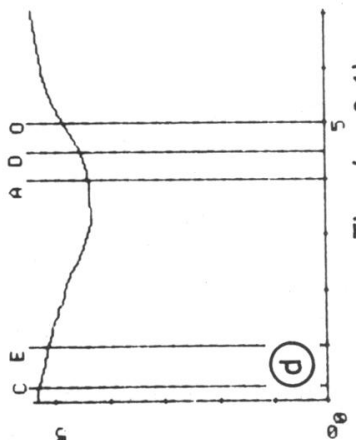

$$
\text { (யว) บo!suวய!! } \wedge 7
$$

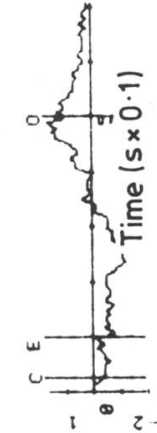

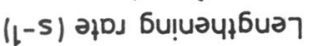

(อ) 
computerised interpretation of a digitised echocardiogram.

\section{Patients and methods}

The study included 50 patients without congestive heart failure or ischaemic heart disease but with serological evidence of past or present Trypanosoma cruzi infection, all of whom had a typical history of exposure to infection, came from rural areas where the disease is heavily endemic, and had positive serum complement fixation and indirect haemagglutination tests performed and interpreted according to the Maekelt method. ${ }^{11}$ Eighteen subjects were excluded because of technical difficulties in recording the apexcardiogram or echocardiogram or because they had left bundle branch block. Only 32 were suitable for computerised echocardiographic analysis, and they were divided into two study groups (groups 1 and 2). In addition two control groups (groups 3 and 4) were also studied.

Group 1 consisted of 20 (six men, 14 women) asymptomatic subjects with Chagas's disease, most of whom were blood donors detected by the blood bank and referred to us. Their mean (SD) age was 38.8 (9.9) years. All had normal electrocardiograms with only occasional unifocal ventricular extrasystoles, normal chest $x$ ray films, and normal $M$ mode and cross sectional echocardiograms.

Group 2 consisted of 12 patients (three men, nine women) with Chagas's disease whose symptoms were directly related to arrhythmias but not to heart failure (New York Association functional class I or II). Their mean age was 45.8 (11.9) years. All had abnormal electrocardiograms consisting of ventricular extrasystoles, most of which were multifocal or in couplets: one had atrial fibrillation and 10 had conduction abnormalities (right bundle branch block (4), left anterior fascicular block (3), isolated left anterior fascicular block (3), abnormal $Q$ waves (3), and nonspecific ventricular repolarisation disorders (10)). All cross sectional echocardiograms showed apical and apicoposterior dyskinesis. These changes were confirmed in seven by left ventricular cineangiograms; all had normal coronary arteriograms.

Group 3-The normal control group consisted of 20 subjects (eight men, 12 women; mean age 30.1 (9.3) years) with no clinical, radiological, or electrocardiographic evidence of heart disease and negative serological tests; all came from urban areas where there were no possibilities of contracting Chagas's infection.

Group 4-The hypertrophic group consisted of 12 patients (six men, six women; mean age 45.1 (14.9) years) of whom six had classic idiopathic hypertrophic cardiomyopathy and six left ventricular hypertrophy secondary to systemic hypertension.
ECHOCARDIOGRAPHY

Echocardiograms with simultaneous apexcardiograms, electrocardiograms (standard lead II), and phonocardiograms (Fig. 1) were performed with the subject in the left lateral position, using a $1.25 \mathrm{~cm}$ diameter, $2.25 \mathrm{MHz}$ transducer with a 1000 cycles/ second repetition frequency and an Irex echocardiograph. The output was displayed on a strip chart recorder operating at a paper speed of $100 \mathrm{~mm} / \mathrm{s}$. A left ventricular echocardiogram of the mitral valve tips clearly showing the onset of opening and providing a clear and constant record of echoes from both the septum and posterior wall endocardium and epicardium was used for further analysis.

The apexcardiograms were recorded using a $3 \mathrm{~cm}$ wide microphone air coupled by $25 \mathrm{~cm}$ rigid plastic tubing to a transducer, with a time constant of $4 \mathrm{~s}$ and a low frequency limit of $0.04 \mathrm{~Hz}$.

The phonocardiograms were recorded with an Irex microphone placed where the high frequency component of the second aortic sound $\left(A_{2}\right)$ could best be recorded.

All recordings were obtained at the end of normal expiration and at least five clear cardiac cycles were recorded. Immediately afterwards, the left ventricular systolic time intervals were measured in the supine position, according to Weissler et al's technique. ${ }^{12}$

\section{Digitising techniques}

The echocardiograms and apexcardiograms were digitised as previously described by Gibson and Brown. ${ }^{1}$ The data processing equipment consisted of an IREX CARDIO 80 microcomputer, a Z80 microprocessor, a graphics/alphanumeric CRT, a digitiser (Summagraphics) $20 \times 20$ inches with 0.01 inch resolution, and a printer-plotter. A semiautomatic computing system was used.

From the digitised data, plots were made of the left ventricular dimension (D), rate of change of dimension $(\mathrm{dD} / \mathrm{dt})$, normalised rate of change of dimension $(\mathrm{dD} / \mathrm{dt} \mathrm{l} / \mathrm{D})$, normalised rate of change of posterior wall thickness (dPW/dt 1/PW), and of the echo dimension apexcardiogram loops. ${ }^{4}$ Figs. 1-3 show examples from subjects in the normal (group 3), asymptomatic (group 1), and arrhythmic (group 2) groups respectively.

Diastolic intervals-Time intervals (ms) were measured $(a)$ from the second aortic sound $\left(\mathrm{A}_{2}\right)$ to the onset of mitral valve opening (isovolumic relaxation time), (b) from minimum left ventricular dimension to $A_{2},(c)$ from minimum left ventricular dimension to mitral valve opening, and $(d)$ between $A_{2}$ and the $O$ point on the apexcardiogram $\left(\mathrm{A}_{2}-\mathrm{O}\right)$. Mean values were obtained for five successive complexes.

Left ventricular dimension changes-Change in left ventricular dimension, expressed as a percentage of 
Table 1 Diastolic time intervals and left ventricular function indices in asymptomatic patients with Chagas's disease (group 1), arrhythmic patients with Chagas's disease (group 2), normal control subjects (group 3), and control subjects with hypertrophy (group 4). Values are mean (ISD)

\begin{tabular}{|c|c|c|c|c|c|c|c|c|c|c|c|}
\hline \multirow[t]{2}{*}{ Group } & \multirow{2}{*}{$\begin{array}{l}\text { No of } \\
\text { patients }\end{array}$} & \multicolumn{4}{|c|}{ Diastolic intervals } & \multicolumn{6}{|c|}{ Left ventricular dimension and function } \\
\hline & & $\operatorname{IVRT}(\mathrm{ms})$ & $\begin{array}{l}A_{2} t o \\
\text { minimum } \\
\text { dimension (ms) }\end{array}$ & $\begin{array}{l}\text { Minimum } \\
\text { dimension to } \\
M V O \text { (ms) }\end{array}$ & $\begin{array}{l}A_{2} \text { to } O \\
\text { point (ms) }\end{array}$ & LVEDD (mm) & $\operatorname{LVESD}(\mathrm{mm})$ & $F S \%$ & $P E P c$ & LVETc & $\begin{array}{l}P E P: L V E T \\
\text { ratio }\end{array}$ \\
\hline $\begin{array}{l}1 \\
2 \\
3 \\
4\end{array}$ & $\begin{array}{l}20 \\
12 \\
20 \\
12\end{array}$ & $\begin{array}{l}72(14)^{\star} \\
81(33) \\
63(11) \\
81(25)^{\star}\end{array}$ & $\begin{array}{l}-23(39)^{\star} \\
20(40)^{\star \star \star}+1 \\
-47(15)^{-1} \\
-1(39)^{\star \star \star}\end{array}$ & $\begin{array}{l}48(39)^{\star \star} \\
+102(50)^{\star \star \star}+1 \\
15(16) \\
80(33)^{\star \star \star}\end{array}$ & $\begin{array}{l}130(20) \\
150(21)^{\star \star \dagger} \\
122(16) \\
151(26)^{\star \star \dagger}\end{array}$ & $\begin{array}{l}50(4) \\
54(7)^{\star} \\
48(4) \\
43(6)^{\star \star}+11 \#+\end{array}$ & $\begin{array}{l}34(4)^{\star} \\
39(9)^{\star} \\
31(4) \\
26(6)^{\star \star}+1+\#+\end{array}$ & $\begin{array}{l}33(5) \\
29(9)^{\star} \\
36(5) \\
40(8)+\# \#\end{array}$ & $\begin{array}{l}126(15) \\
125(21) \\
120(11) \\
146(77)\end{array}$ & $\begin{array}{l}419(19) \\
400(33) \\
416(13) \\
397(88)\end{array}$ & $\begin{array}{l}0.32(0.06) \\
0.34(0.1) \\
0.30(0.04) \\
0.34(0.11)\end{array}$ \\
\hline
\end{tabular}

Statistical difference from group 3: ${ }^{\star \star \star} p<0.001 ;{ }^{\star \star} p<0.01 ;{ }^{\star} p<0.05$; from group 1: $\#+p<0.001 ; \# p<0.01 ;$ tp $<0.05$; and from group 2: \#p<0.001; $\# \mathrm{p}<0.01$.

MVO, mitral valve opening; LVEDD, left ventricle end diastolic dimension; LVESD, left ventricle end systolic dimension; FS\%, fractional shortening; PEPc, pre-ejection period corrected; LVETc, left ventricular ejection time corrected; PEP:LVET, ratio of pre-ejection period to left ventricle ejection time.

total dimension change during the cardiac cycle, was measured for each of the following intervals: $(a)$ isovolumic contraction (between $\mathrm{C}$ and $\mathrm{E}$ points), (b) the apexcardiogram downstroke (between minimum dimension and the $\mathrm{O}$ point, pre-O),(c) the isovolumic relaxation time, $(d)$ and atrial systole (between the beginning of the electrocardiogram $P$ wave and the beginning of the $Q$ wave at the end of the cycle).

The "a": $H$ ratio of the apexcardiogram, which represents the relative magnitudes of the "a" wave in relation to the total outward movement and the "a":D ratio taken as the ratio between the "a" wave height and total diastolic deflection (D). ${ }^{13}$

Left ventricular cavity dynamics-(a) Left ventricular end diastolic dimension (LVEDD) was measured at the beginning of the $Q$ wave; $(b)$ left ventricular end systolic dimension (LVESD) was taken as the minimum systolic dimension; (c) fractional shortening (\%FS) was calculated by substracting the end systolic dimension (LVESD) from the end diastolic dimension (LVEDD), and expressing it as a percentage of the LVEDD (LVEDD-LVESD/LVEDD $\times 100 \%$ ); (d) peak rate of increase in left ventricular dimension was calculated as the highest positive value of the dimension change curve in diastole; and (e) rapid filling period was arbitrarily defined as the interval between the minimum dimension and reduction to $20 \%$ of the peak rate of dimensional increase. ${ }^{1}$

Left ventricular posterior wall dynamics-(a) normalised peak rate of posterior wall thinning was taken as the lowest negative value of the mean curve of change in posterior wall thickness during diastole; and $(b)$ duration of early thinning of the posterior wall was taken as the interval between maximum posterior wall thickness and the peak rate of posterior wall thinning.

\section{VALIDITY AND REPRODUCIBILITY OF METHODS}

Validation of echocardiographic measurements of the left ventricular minor axis and its rate of change has been established by comparison with angiographic data from previous studies. ${ }^{14} 15$

Reproducibility was assessed as the root mean square difference between pairs of determination of left ventricular dimension at end systole and end diastole and of peak rate of increase in left ventricular dimension during filling. These calculations were performed for 20 pairs of measurements made by two observers on the same recording and also in 10 patients between pairs of recordings made at different times in the same patient. For duplicate determinations on the same recording the mean square difference was $1.7 \mathrm{~mm}$ for end systole and $1.8 \mathrm{~mm}$ for end

Table 2 Left ventricular $(L V)$ percentage dimensional changes, left ventricular $(L V)$ cavity dymamics, and " $a$ " wave (apexcardiogram) in asymptomatic patients with Chagas's disease (group 1), arrhythmic patients with Chagas's disease (group 2), normal control subjects (group 3), and control subjects with hypertrophy (group 4). Values are mean (ISD)

\begin{tabular}{|c|c|c|c|c|c|c|c|c|}
\hline \multirow[t]{2}{*}{ Group } & \multicolumn{4}{|c|}{$L V$ dimension change } & \multicolumn{2}{|c|}{$L V$ cavity dynamics } & \multicolumn{2}{|l|}{ " $a$ " wave } \\
\hline & $C E(\%)$ & $P R E-O(\%)$ & $I V R(\%)$ & $\begin{array}{l}\text { Atrial systole } \\
\text { (\%) }\end{array}$ & $\begin{array}{l}\text { Peak rate of } \\
\text { dimension } \\
\text { increase }(\mathrm{cm} / \mathrm{s})\end{array}$ & $\begin{array}{l}\text { Rapid filling } \\
\text { period (ms) }\end{array}$ & “ $a$ ":H(\%) & “a”:D(\%) \\
\hline $\begin{array}{l}1 \\
2 \\
3 \\
4\end{array}$ & $\begin{array}{c}8.8(8.4) \\
15.6(12.4)^{\star} \\
6.9(8.9) \\
23.0(22.7)^{\star} \dagger\end{array}$ & $\begin{array}{l}37.2(10.6) \\
48.8(9.7)^{\star \star \star}+t \\
34.3(10 \cdot 1) \\
41.5(16.8)\end{array}$ & $\begin{array}{c}6.9(6.0)^{\star \star \star} \\
19.5(18.0)^{\star \star \dagger} \\
1.5(2 \cdot 1) \\
14.4(9.1)^{\star \star \star \dagger}\end{array}$ & $\begin{array}{l}21.2(9.3)^{\star} \\
17.6(9.4) \\
15.8(6.2) \\
23.8(13.2)\end{array}$ & $\begin{array}{l}12.0(3.1)^{\star \star \star} \\
10.1(3.4)^{\star \star \star} \\
16.0(3.0) \\
10.9(3.7)^{\star \star \star}\end{array}$ & $\begin{array}{l}177 \cdot 1(72 \cdot 2)^{\star \star} \\
225 \cdot 1(69 \cdot 1)^{\star \star \star} \\
125 \cdot 7(29 \cdot 2) \\
176.9(63 \cdot 1)^{\star}\end{array}$ & $\begin{array}{l}9.1(5.4) \\
19.1(11.3)^{\star \star} \dagger \\
7.5(3.5) \\
19.9(9.4)^{\star \star \star}+1 t\end{array}$ & $\begin{array}{l}29.5(13.0) \\
51.5(15.8)^{\star \star \star} \mathrm{H} \\
23.6(9.3) \\
44.7(13.5)^{\star \star \star} \mathrm{H}\end{array}$ \\
\hline
\end{tabular}

Statistical difference from group $3: \star \star \star p<0.001 ; \star \star p<0.01 ;{ }^{\star} \mathrm{p}<0.05 ;$ and from group $1: \mathrm{ttp}<0.001 ;+t \mathrm{p}<0.01 ; \mathrm{tp}<0.05$.

"a":H, ratio of "a" wave to total apexcardiogram height; " $a$ ": $\mathrm{D}$, ratio of " $\mathrm{a}$ " wave to total diastolic deflection of apexcardiogram; CE\%, change in $\mathrm{LV}$ dimension between $\mathrm{C}$ and $\mathrm{E}$ points of apexcardiogram (expressed as percentage of total dimension change); IVR, isovolumic relaxation time. 
Table 3 Posterior wall (PW) dymamics in asymptomatic patients with Chagas's disease (group 1), arrhythmic patients with Chagas's disease (group 2), normal control subjects (group 3), and control subjects with hypertrophy (group 4). Values are mean (1SD)

\begin{tabular}{lllc}
\hline Group & $\begin{array}{l}\text { PW thickness } \\
\text { diastole }(m m)\end{array}$ & $\begin{array}{l}\text { Peak rate of }(N) \\
P W \text { thinning }\left(s^{-1}\right)\end{array}$ & $\begin{array}{c}\text { Duration of } P W \\
\text { thinning }(m s)\end{array}$ \\
\hline 1 & $7.5(1.6)$ & $5.1(1.9)^{\star \star}$ & $84.3(46.4)^{\star}$ \\
2 & $7.4(1.5)$ & $3.5(1.9)^{\star \star \star \dagger}$ & $114.1(40.4)^{\star \star \star}$ \\
3 & $6.9(1.4)$ & $6.7(1.8)$ & $59.1(17.1)$ \\
4 & $12.3(3.5)^{\star \star \star}+\# \# \#$ & $3.6(1.7)^{\star \star \star \dagger}$ & $86.2(54.5)$ \\
\hline
\end{tabular}

Statistical difference from group $3: \star \star \star \mathrm{p}<0.001 ; \star \star \mathrm{p}<0.01$; ${ }^{\star} p<0.05$; from group $1:+1+p<0.001 ; \nmid p<0.05$; and from group 2 : $\# p<0.001$.

$\mathrm{N}$, normalised (dPW/dt $1 / \mathrm{PW})$.

diastole difference and $1.6 \mathrm{~cm} / \mathrm{s}$ for peak rate of increase of left ventricular dimension.

\section{STATISTICAL METHOD}

Normal values were considered to be those found between two standard deviations of the mean values in the normal group. The statistical analysis of the differences between means was determined by Student's $t$ test.

\section{Results}

Tables 1-3 and Figs. 4-8 show the results (mean

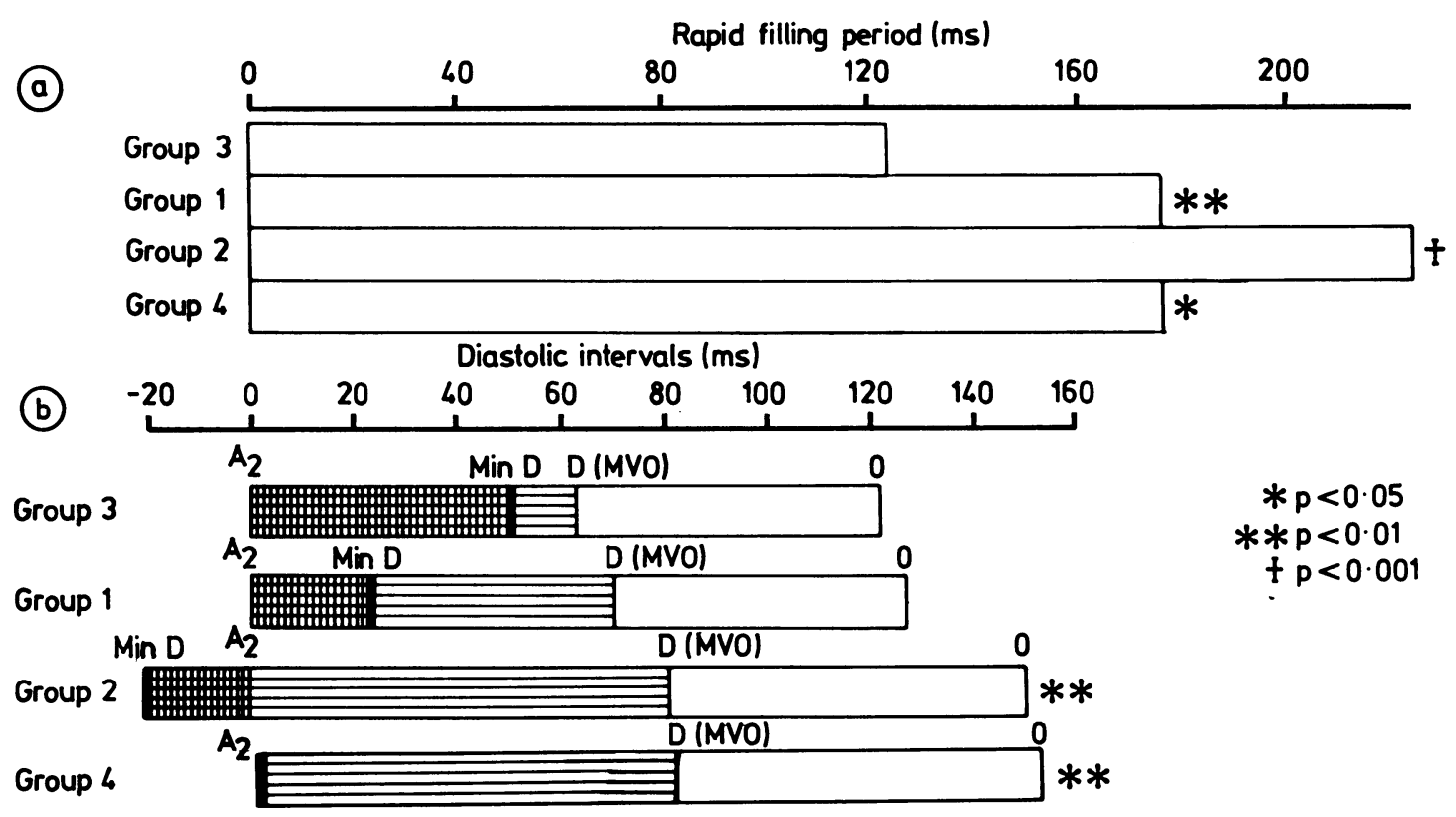

Fig. 4 (a) Duration of rapid filling period and (b) diastolic intervals in the four groups studied. The significantly prolonged rapid filling time of the asymptomatic and arrhythmic patients with Chagas's disease (groups 1 and 2) and the control group with hypertrophy (group 4) compared with the normal control group (group 3) may be readily seen as well as the progressively delayed $A_{2}$ mitral valve opening (MVO) and prolonged isovolumic relaxation and $\mathrm{A}_{2} \mathrm{O}$ intervals.
(SD)) in the asymptomatic study group (group 1), the study group with arrhythmias (group 2), the normal control group (group 3), and the hypertrophic control group (group 4). Group 3 had diastolic intervals and changes in left ventricular dimension, left ventricular cavity size, and posterior wall dynamics similar to those reported by others. ${ }^{3} 16$

\section{GROUP 1}

Although the left ventricular end diastolic dimension, the end diastolic thickness of the posterior wall, the percentage fractional shortening, and the systolic time intervals were normal with respect to the control group, the following significant abnormalities were found (Tables 1-3):

Diastolic intervals-Isovolumic relaxation time was prolonged $(p<0.05)$ and mitral valve opening and aortic valve closure were delayed in relation to minimum dimension ( $p<0.01$ and $p<0.05$ respectively) (Figs. 4 and 5).

Changes in left ventricular dimension-There was a significant abnormal increase in left ventricular dimension during isovolumic relaxation time $(p<0.001)$. Increased change in dimension was found during atrial systole $(p<0.05)$ (Fig. 6). As regards the " $\mathrm{a}$ ": $\mathrm{H}$ and " $\mathrm{a}$ ": $\mathrm{D}$ ratios in the apexcardiogram, although there was no significant change, values 2 standard deviations above the mean for the normal 


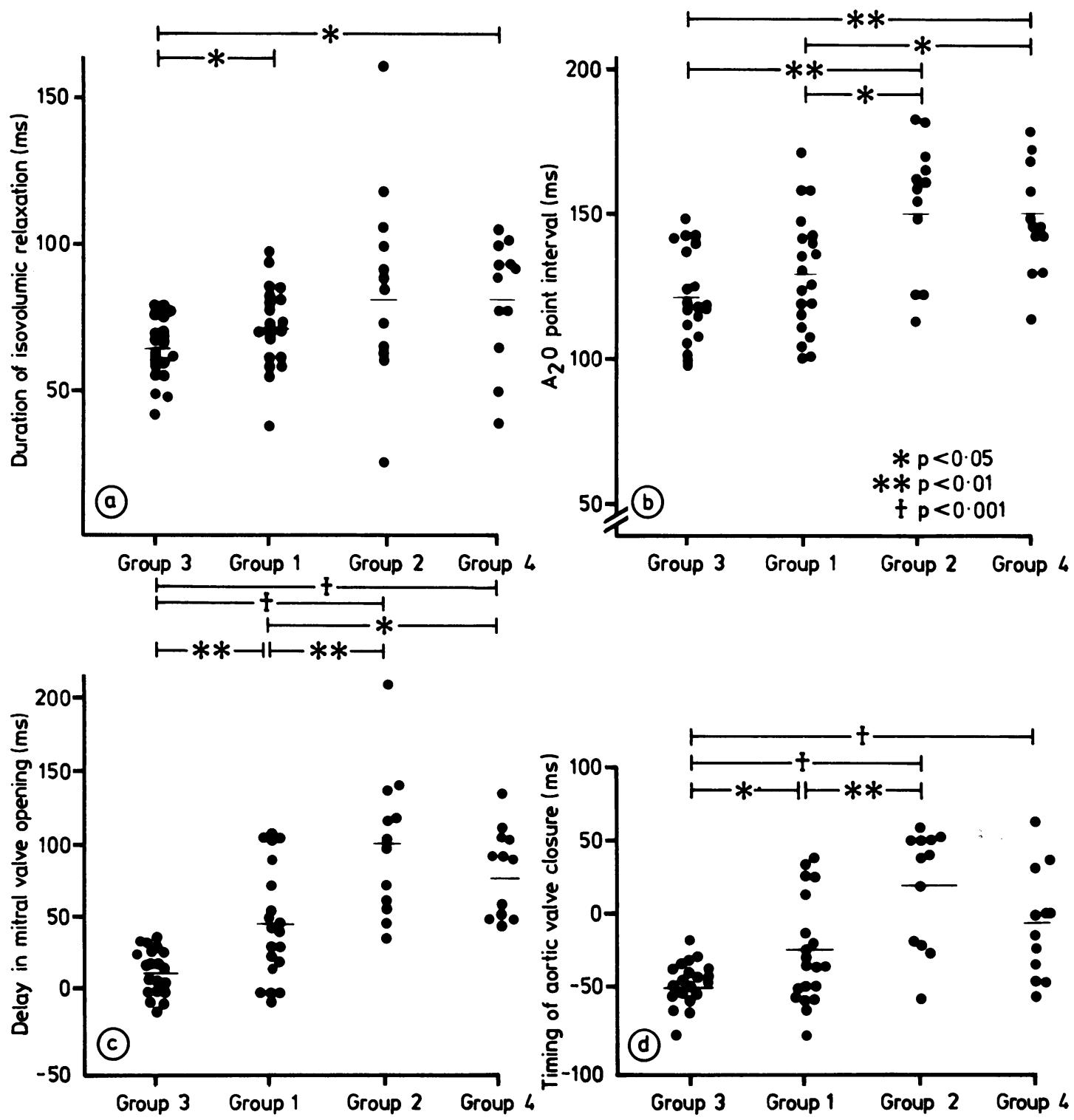

Fig. 5 (a) Duration of isovolumic relaxation, (b) duration of $\mathrm{A}_{2} \mathrm{O}$ point interval, (c) timing of mitral valve opening, (d) timing of aortic valve closure with respect to minimal dimension in normal control subjects (group 3), asymptomatic and arrhythmic Chagas's heart disease patients (groups 1 and 2), and hypertrophic control subjects (group 4).

group were found in seven out of 20 patients.

Left ventricular cavity dynamics-Left ventricular end systolic dimension was significantly increased $(p<0.05)$, the peak rate of increase in dimension was reduced $(p<0.001)$, and the duration of the rapid filling period was significantly prolonged $(p<0.01)$ (Figs. 7 and 8).

Left ventricular posterior wall dynamics-The nor- malised peak rate of posterior wall thinning was reduced $(p<0.01)$ and early thinning of the posterior wall was prolonged $(p<0.05)$ (Figs. 7 and 8 ).

GROUP 2

This group had a slight increase in both the left ventricular end diastolic dimension and left ventricular 


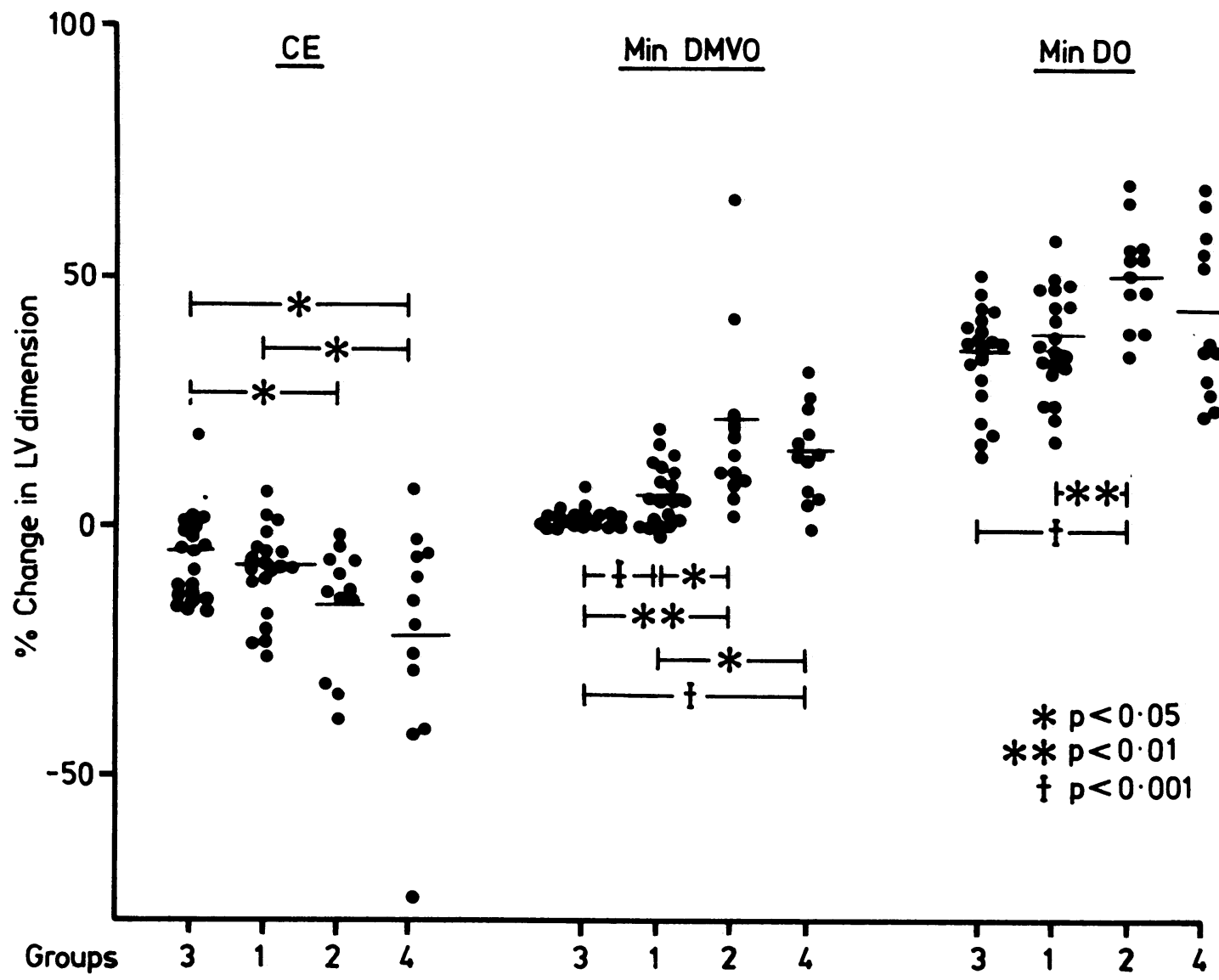

Fig. 6 Change in $L V$ dimension (expressed as percentage of total dimension change) between $C$ point (apexcardiogram) and $E$ point $(C E)$ and between minimum dimension and mitral valve opening (min DMVO) and between minimum dimension and $O$ point (pre-O) (min DO) in normal control subjects (group 3), asymptomatic and arrhythmic Chagas's heart disease patients (groups 1 and 2), and hypertrophic control subjects (group 4).

end systolic dimension (53.8 (6.6) $\mathrm{mm}$ and 38.6 (8.9) $\mathrm{mm})$ and a slight decrease in fractional shortening (29 (9)\%); nevertheless, systolic time intervals and posterior wall thickness remained normal.

The abnormal values for all indices of diastolic function seen in group 1 were of a greater magnitude in group 2 who also had $(a)$ increased duration of the $\mathrm{A}_{2}-\mathrm{O}$ interval $(\mathrm{p}<0.01$ and $\mathrm{p}<0.05$ vs groups 3 and 1), (b) abnormal reduction in left ventricular dimension during the apexcardiogram upstroke $(p<0.05$ vs group 3) as well as an abnormal increase during the apexcardiogram downstroke during isovolumic relaxation time ( $p<0.01$ and $p<0.05$ vs groups 1 and 3 ) and before the $O$ point (pre- $O)(p<0.001$ and $p<0.01$ vs group 1 and 3 ), and (c) an increase in the " $a$ ": $H$ ratio $(p<0.01$ and $p<0.05$ vs groups 1 and 3) and "a":D ratio in the apexcardiogram ( $\mathrm{p}<0.001$ vs groups 1 and 3) (Tables 1-3, Figs. 4-8).

\section{GROUP 4}

Left ventricular end diastolic and left ventricular end systolic dimensions were reduced ( $p<0.01$ vs group 3 and $p<0.001$ vs groups 1 and 2 ). The fractional shortening and the systolic intervals were normal. End diastolic thickness of the left ventricular posterior wall was increased ( $<<0.001$ vs groups 1, 2, and 3). Diastolic function abnormalities similar to those in group 2 were found; there was, however, less delay in aortic valve closure and mitral valve opening. The increase in dimension during the apexcardiogram downstroke was not significant and the rapid filling period was less prolonged (Tables 1-3, and Figs. 4-8). 

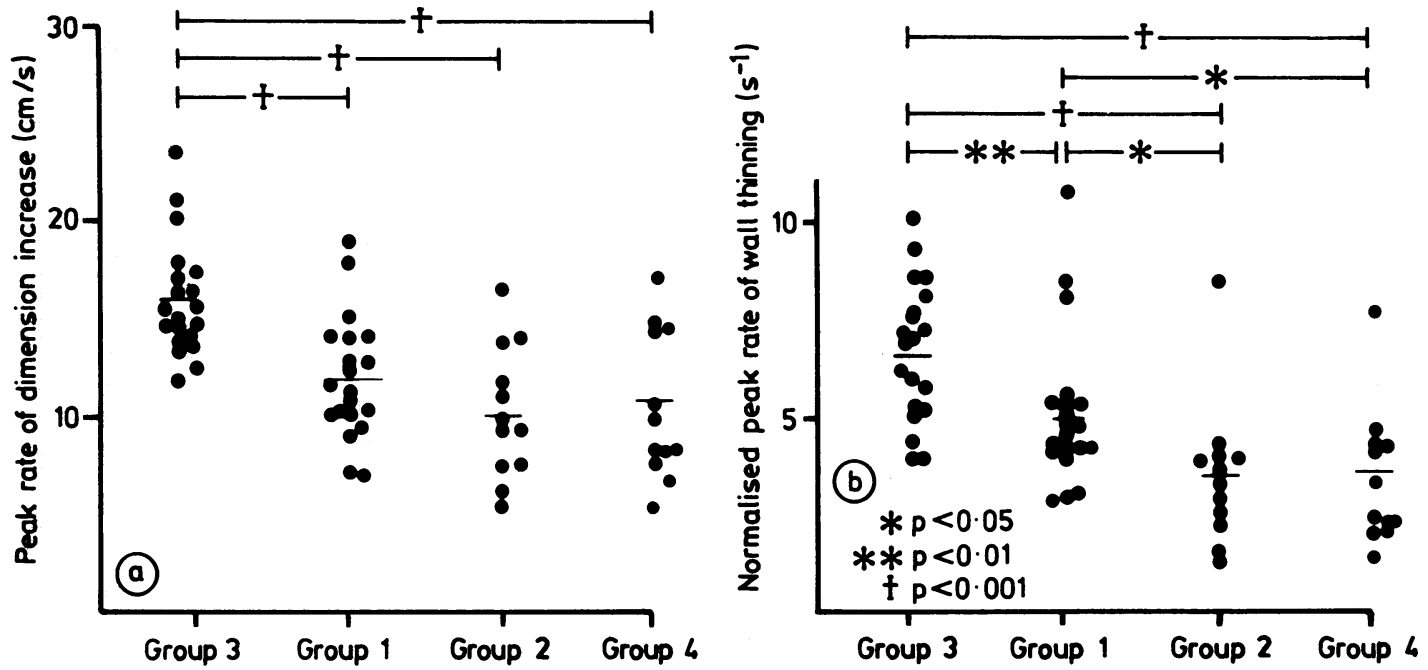

Fig. 7 (a) Peak rate of increase in left ventricular ( $L V)$ dimension in diastole and (b) normalised peak rate of wall thinning in normal control subjects (group 3), asymptomatic and arrhythmic Chagas's heart disease patients (groups 1 and 2), and hypertrophic control subjects (group 4).

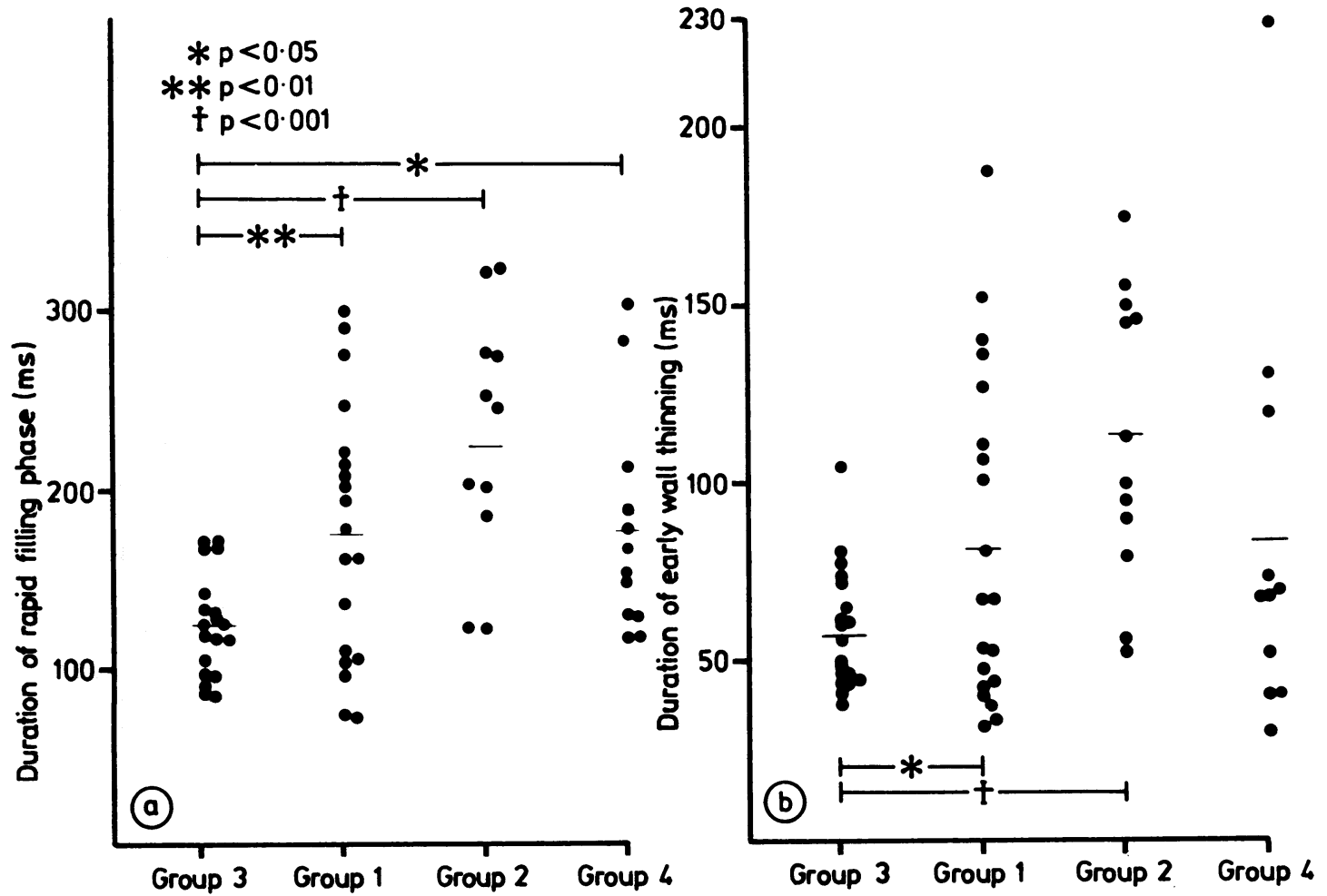

Fig. 8 (a) Duration of rapid filling and (b) duration of early wall thinning in normal control subjects (group 3), asymptomatic and arrhythmic Chagas's heart disease patients (groups 1 and 2), and hypertrophic control subjects (group 4). 


\section{Discussion}

Computerised echocardiographic interpretation is an excellent tool for studying left ventricular diastolic function because it provides not only a continuous record of changes in dimension, wall thickness, and instantaneous dynamics but also allows us to pinpoint the moment mitral valve opening begins and thus to study left ventricular relaxation and filling. It has been useful as a non-invasive method of studying early changes in ventricular function in subjects with ischaemic and valvar heart disease and hypertrophic cardiomyopathy and could be used in the study of other heart diseases. ${ }^{4} \mathrm{We}$ found it especially useful in patients with early Chagas's heart disease for studying inco-ordinate contraction, which has previously been reported by our group and others. ${ }^{6-917}$

Interestingly, important diastolic function abnormalities were found even in the asymptomatic patients with Chagas's disease (group 1) in whom clinical examination, electrocardiograms, chest $x$ ray films, and $M$ mode and cross sectional echocardiograms had failed to show any signs of heart disease. The abnormalities were less severe in this group than in those with arrhythmias (group 2).

Firstly, the abnormal diastolic intervals included delayed closure of the aortic valve, delayed mitral valve opening, and prolonged isovolumic relaxation. The delay in aortic valve closure is explained by inco-ordination due to segmental contractility disorders as there are areas of myocardium with delayed or abnormal movements which provoke persistent tension, thus prolonging and delaying the end of ejection. ${ }^{3}$ Delayed mitral valve opening would thus be explained not only by the delayed aortic valve closure but by the prolonged isovolumic relaxation time itself.

Secondly, the abnormal changes in left ventricular dimension during the apexcardiogram upstroke (isovolumic contraction), the downstroke (early relaxation), or both consisted of a significant reduction in dimension during the former and an abnormal increase during the latter; when both abnormalities were present, reduction during isovolumic contraction was always accompanied by increase during relaxation. These abnormal dimensional changes were the result of disturbances of function. A decrease in dimension during isovolumic contraction could reflect assynchronous onset of contraction, with areas of myocardium developing early tension and contraction, whereas an increase in dimension during relaxation would reflect increased outward movement of the posterior wall before mitral valve opening occurs, accompanied by a change in isovolumic shape. A similar explanation has been suggested for ischaemic patients with inco-ordinate contraction ${ }^{4}$; however, invasive studies would be needed for confirmation.
Combellas, Puigbo, Acquatella, Tortoledo, Gomez

Thirdly, the abnormal left ventricular cavity and posterior wall dynamics included prolonged duration of rapid filling and reduced dimensional increase peak rate accompanied by prolonged and reduced posterior wall thinning. This tendency towards early involvement of the posterior wall or apical region in Chagas's heart disease or both had already been confirmed by cineventriculograms, $M$ mode and cross sectional echocardiograms, and radionuclide studies ${ }^{6-8}$ and represents the pathological substratum of posterior wall thinning or aneurysms. ${ }^{18}$

In the patients with arrhythmias who already showed signs of heart disease, but without congestive heart failure, the abnormalities of diastolic function were more severe and widespread. Significant differences in relation to the abnormal changes in the asymptomatic group were observed and were also accompanied by other changes, both in early and end diastole. The former consisted of a significant lengthening of the $A_{2}-O$ interval accompanied by an abnormal increase in the left ventricular dimension before the $\mathrm{O}$ point (increased pre-O dimension) and the latter consisting of an increase in the apexcardiogram " $a$ " waye. The first changes would be secondary to a greater abnormality in the velocity and duration of rapid filling ${ }^{19}$ and the second would be a sign of a significant atrial systole, during which the left ventricular dimensional change was relatively small and reflected greater resistance to filling during end diastole. Both changes indicate myocardial restriction due to reduced distensibility in Chagas's disease. A good correlation has been reported between increases in the "a" wave, both the "a"::H and the "a":D ratios, with diastolic compliance or distensibility, determined by invasive methods in subjects with dilated cardiomyopathy. ${ }^{13}$ These abnormal findings in the group with arrhythmias were similar to those in the control group with left ventricular hypertrophy having a known pattern of diastolic abnormalities. ${ }^{20-23}$

Similar changes have also recently been described in subjects with aortic valve stenosis and severe diabetes. ${ }^{22} 24$ Although these findings are not specific to Chagas's disease, there are certain differentiating characteristics. The degree of assynchronism (delayed aortic valve closure and delayed mitral valve opening) is greater in patients with Chagas's disease, and the degree of the dimensional changes during the isovolumic periods (both contraction and relaxation) is greater than in subjects with hypertrophy. Moreover, although there is some similarity in patients with ischaemic heart disease as far as the degree of assynchronism and dimensional changes are concerned, ${ }^{25}$ in Chagas's disease the isovolumic relaxation period is prolonged and the filling abnormalities are more severe. It is important to point out that a diagnosis of coronary disease can be excluded as a 
cause in this series because of the absence of symptoms, mean age $<43$ years, normal coronary angiograms in seven out of $12(58 \%)$ patients in the arrhythmic group, and positive serology for Chagas's disease in $100 \%$ of the patients.

Abnormalities in diastolic function have been ascribed to altered myocardial properties (ischaemic disease, hypertrophy) 20212627 or to microvascular involvement (diabetes). ${ }^{24}$

In Chagas's disease these abnormalities are due to oedema, inflammatory cell infiltration, and destruction of the myocardial fibres. In the more advanced stages, fibrous replacement of myocardial fibres might be a cause contributing to myocardial rigidity.

These findings lead us to believe that the initial manifestation of Chagas's disease is predominantly a diastolic rather than a systolic dysfunction and that only years later the symptoms secondary to severe impairment of pumping or systolic function prevail.

It is a well known fact that in Chagas's disease the initial infection, easily detected by serological tests, is often followed by a latent period which lasts for years or even decades. It is important during this period to detect any sign of heart disease. This not only permits timely therapeutic measures to be taken, such as parasiticide drugs, but also a better assessment of these measures and further knowledge as far as prognosis and the evolution of this disease is concerned.

To our knowledge there is no report of studies of diastolic function in Chagas's disease using noninvasive techniques. Carrasco et al found abnormal and progressive changes in left ventricular systolic function and distensibility using invasive studies. ${ }^{9}$

\section{References}

1 Gibson DG, Brown D. Measurement of instantaneous left ventricular dimension and filling rate in man, using echocardiography. Br Heart $\mathcal{F}$ 1973; 35: 1141-9.

2 Upton MT, Gibson DG. The study of left ventricular function from digitized echocardiograms. Prog Cardiovasc Dis 1978; 20: 359-84.

3 Traill TA, Gibson DG. Left ventricular relaxation and filling: study by echocardiography. In: Yu PN, Goodwin JF, eds. Progress in cardiology. vol 8. Philadelphia: Lea and Febriger, 1979:39-72.

4 Venco A, Gibson DG, Brown DJ. Relation between apexcardiogram and changes in left ventricular pressure and dimension. $\mathrm{Br}$ Heart f 1977; 39: 117-25.

5 Gibson DG, Traill TA, Brown DJ. Changes in left free wall thickness in patients with ischaemic heart disease. $\mathrm{Br}$ Heart $\mathrm{f}$ 1977; 39: 1312-8.

6 Puigbo JJ, Pisani F, Boccalandro I, Blanco P, Machado I, Valero JA. Estudio de la cardiopatia chagásica crónica Empleo de la cinengiocardiografía. Acta Medica Venezolana 1968; 15: 339-50.

7 Acquatella H, Schiller NB, Puigbó JJ, et al. M-mode and twodimensional echocardiography in chronic Chagas' heart disease. Circulation 1980; 62: 787-99.

8 Arreaza N, Puigbó JJ, Acquatella H, et al. Radionuclide evaluation of left-ventricular function in chronic Chagas' cardiomyopathy. F Nucl Med 1983; 24: 563-7.

9 Carrasco HA, Barboza J, Inglessis G, Fuenmayor A, Molina C. Left ventricular cineangiography in Chagas' disease: detection of early myocardial damage. Am Heart f 1982; 104: 595-602.

10 Salazar A, Puigbo JJ, Anselmi A, Giordano H, Combellas I. Non-invasive techniques in early stages of chronic Chagas' cardiomyopathy. In: Abstracts of the VIII World Congress of Cardiology, Tokyo, fapan. No 818. 1978:294.

11 Maekelt GA. Die Komplementbindungsreaktion der Chagas krankheit. Zeitschrift fur Tropenmedizin und Parasitologie 1960; 11: 152-86.

12 Weissler AM, Harris WS, Schoenfeld CD. Bedside technics for the evaluation of ventricular function in man. Am $\mathcal{F}$ Cardiol 1969; 23: $577-83$.

13 Manolas J, Krayenbuehl HP, Rutishauser W. Use of apexcardiography to evaluate left ventricular diastolic compliance in human beings. Am $\mathcal{F}$ Cardiol 1979; 43: 939-45.

14 Gibson DG, Brown DJ. Measurement of peak rates of left ventricular wall movement in man: comparison of echocardiography with angiography. Br Heart $\mathcal{F}$ 1975; 37: 677-83.

15 Feigenbaum H, Popp RL, Wolfe SB, et al. Ultrasound measurements of the left ventricle: a correlative study with angiocardiography. Arch Intern Med 1972; 129: 461-7.

16 Chen W, Gibson D. Relation of isovolumic relaxation to left ventricular wall movement in man. Br Heart f 1979; 42: 51-6.

17 Fontes VF, Sousa JE, Kormann DS, Jatene A. Avaliacao cineangiocardiografica da cardiopatie chagásica crónica. Arq Bras Cardiol 1972; 25: 375-81.

18 Suarez JA, Puigbo JJ, Nava Rhode JR, Valero JA, Gil Yepez C. Estudio anatomopatológico de 210 casos de miocardiopatia en Venezuela. Acta Médica Venezolana 1968; 15: 320-30.

19 Mattheos M, Shapiro E, Oldershaw PJ, Sacchetti R, Gibson DG. Non-invasive assessment of changes in left ventricular relaxation by combined phono-, echo- and mechanocardiography. $\mathrm{Br}$ Heart f 1982; 47: 253-60.

20 St John Sutton MG, Tajik AJ, Gibson DG, Brown DJ, Seward JB, Giuliani ER. Echocardiographic assessment of left ventricular filling and septal and posterior wall dynamics in idiopathic hypertrophic subaortic stenosis. Circulation 1978; 57: 512-20.

21 Sanderson JE, Traill TA, St John Sutton MG, Brown DJ, Gibson DG, Goodwin JF. Left ventricular relaxation and filling in hypertrophic cardiomyopathy. Br Heart f 1978; 40: 596-601.

22 Gibson DG, Traill TA, Hall RJC, Brown DJ. Echocardiographic features of secondary left ventricular hypertrophy. $\mathrm{Br} \mathrm{Heart} \mathcal{f}$ 1979; 41: 54-9.

23 Hanrath P, Mathey DG, Siegert R, Bleifeld. P. Left ventricular relaxation and filling pattern in different forms of left ventricular hypertrophy: an echocardiographic study. Am $\mathcal{F}$ Cardiol 1980; 45: $15-23$.

24 Shapiro LM. Echocardiographic features of impaired ventricular function in diabetes mellitus. Br Heart $\mathcal{F}$ 1982; 47: 439-44.

25 Upton MT, Gibson DG, Brown DJ. Echocardiographic assessment of abnormal left ventricular relaxation in man. $\mathrm{Br} \mathrm{Heart} \mathcal{f}$ 1976; 38: 1001-9.

26 Traill TA, Gibson DG, Brown DJ. Study of left ventricular wall thickness and dimension changes using echocardiography. $\mathrm{Br}$ Heart f 1978; 40: 162-9.

27 Gamble WH, Shaver JA, Alvares RF, Salerni R, Reddy PS. A critical appraisal of diastolic time intervals as a measure of relaxation in left ventricular hypertrophy. Circulation 1983; 68: 76-87. 